\title{
Faktor - Faktor yang mempengaruhi Kinerja pada Karyawan Bank di Batam
}

\section{YUSWARDI, SE., MM}

Universitas Internasional Batam

yuswardi003@gmail.com

\begin{abstract}
Abstrak Penelitian ini bertujuan untuk mengetahui pengaruh dari variabel kompensasi, komitmen organisasional, motivasi dan pelatihan kerja terhadap kinerja karyawan bank nasional yang ada di Batam.

Penelitian ini dilakukan dengan metode survei melalui penyebaran kuesioner kepada 250 responden yang merupakan karyawan dari lima bank terbesar di Indonesia, yaitu Bank Mandiri, Bank Rakyat Indonesia, Bank Central Asia, Bank Negara Indonesia dan Bank CIMB Niaga yang berada di Batam. Setelah kuesioner disebarkan dan dikumpulkan kembali oleh penulis, berhasil didapatkan 240 kuesioner yang diisi dengan lengkap sehingga bisa dilakukan pengujian data regresi oleh penulis dengan menggunakan program SPSS. Dari hasil pengolahan data dengan program SPSS diketahui bahwa terdapat hubungan antara semua variabel yang diteliti.

Hasil penelitian ini menekankan tentang pentingnya bagi manajemen bank nasional untuk memberikan perhatian yang lebih besar pada variabel yang diteliti diatas. Karena semua variabel tersebut diatas berhubungan erat dengan kinerja karyawan, sehingga bila perusahaan ingin meningkatkan kinerja karyawannya maka hal tersbut diatas harus ditingkatkan dan diperbaiki.
\end{abstract}

Kata Kunci bank, kompensasi, motivasi, komitmen organisasional dan kinerja karyawan

\section{PENDAHULUAN}

Menghadapi persaingan global yang makin intensif, perkembangan teknologi yang cepat berkembang, perubahan demografi, keadaan ekonomi yang tidak menentu dan perubahan dinamis lainnya telah memicu perubahan kondisi lingkungan yang mulanya stabil, dapat diprediksi berubah menjadi lingkungan kerja yang penuh ketidakpastian, komplek dan cepat berubah. Karyawan yang kurang diperhatikan oleh organisasi dapat menyebabkan ketidakpuasan kerja karyawan. Ketidakpuasan tersebut sering ditunjukkan dalam bentuk sering unjuk rasa, tingkat keluar masuk karyawan yang tinggi, sering tidak masuk kerja, motivasi yang rendah, cepat lelah dan bosan, dan tidak peduli dengan lingkungan sekitar (Iqbal et al., 2012). 
Bidang perbankan merupakan salah satu kegiatan usaha yang turut berperan dalam usaha mensukseskan pembangunan nasional selain untuk mengumpulkan dana berupa investasi demi pembangunan nasional. Bank juga berperan menyalurkan dana untuk ikut serta membantu perkembangan usaha masyarakat. Lingkungan eksternal yang dinamis dan persaingan perbankan yang semakin ketat menuntut setiap bank untuk dapat memberikan pelayanan terbaik kepada semua nasabah. Sehingga nasabah bank dapat mengakses data transaksi dengan lebih mudah, dimana dan kapan saja. Agar mampu memenangkan persaingan di bidang perbankan yang semakin ketat diperlukan sumber daya manusia (SDM) yang memiliki kompetensi kerja dan komitmen terhadap organisasi yang besar sehingga karyawan mampu memberikan kontribusi untuk kemajuan organisasi (Ali et al., 2011).

Komitmen organisasional dipandang oleh Memari et al. (2013) sebagai suatu orientasi nilai terhadap organisasi yang menunjukkan individu sangat memikirkan dan mengutamakan pekerjaan dan organisasi. Individu akan berusaha memberikan segala usaha yang dimilikinya dalam rangka membantu organisasi mencapai tujuannya. Memari et al. (2013) juga mendefinisikan komitmen organisasional sebagai sikap yang muncul dari proses yang disebut sebagai identifikasi yang terjadi ketika seseorang mempunyai pengalaman dengan sesuatu, seseorang, atau beberapa ide sebagai bentuk perpanjangan dari dirinya.

\section{LANDASAN TEORI}

\section{Kinerja Karyawan}

Kinerja karyawan mengacu kepada pencapaian tugas-tugas yang membentuk hasil dari sebuah pekerjaan karyawan (Hameed et al. 2012). Pada dasarnya kinerja karyawan merupakan hasil proses yang kompleks, baik berasal dari diri pribadi karyawan (internal factor), keadaan lingkungan perusahaan (external factor) maupun upaya strategis dari perusahaan. Faktor- faktor internal misalnya motivasi, tujuan, harapan, dan lain-lain. Faktor eksternal adalah lingkungan fisik dan non fisik perusahaan. Kinerja yang baik tentu saja merupakan harapan bagi semua perusahaan dan institusi yang mempekerjakan karyawan, sebab kinerja karyawan ini pada akhirnya diharapkan dapat meningkatkan kinerja perusahaan secara keseluruhan. Jika kinerja karyawan baik maka kinerja perusahaan akan baik pula, demikian sebaliknya, kalau kinerja karyawan tidak baik maka kurang baik pula kinerja perusahaan (Ali et al., 2011). Menurut Rizwan et al. (2014), kinerja adalah melakukan suatu kegiatan sesuai dengan tanggung jawabnya dengan hasil seperti yang diharapkan. Dinyatakan bahwa kinerja adalah hasil kerja yang dapat dicapai oleh seseorang atau sekelompok orang dalam suatu organisasi, sesuai dengan wewenang dan tanggung jawab masing-masing, dalam rangka upaya mencapai tujuan organisasi, tidak melanggar hukum dan sesuai dengan moral maupun etika.

Komitmen organisasional juga didefinisikan oleh Ahmad et al., (2014) sebagai bentuk kecintaaan karyawan terhadap tempat kerjanya. Pekerja yang mempunyai komitmen terhadap organisasi senang untuk menjadi anggota organisasi, percaya terhadap organisasi dan mempunyai perasaan yang baik tentang organisasi, dan bersedia bersedia membela organisasi, dan mau melakukan sesuatu yang baik untuk organisasi. Komitmen organisasional didefinisikan sebagai keterlibatan dirinya kedalam bagian organisasi, yang dicirikan oleh penerimaan nilai dan tujuan organisasi, kesediaan 
berusaha demi organisasi dan keinginan mempertahankan keanggotaan dalam organisasi. (Ahmad et al., 2014).

Karyawan dapat diberikan motivasi dengan memberikan apa yang menjadi keinginannya. Seorang karyawan yang termotivasi, akan bekerja keras melakukan pekerjaannya dengan baik untuk keberhasilan perusahaan. Kerja keras yang dilakukan dengan adanya dorongan atau motivasi akan menghasilkan sebuah kepuasan tersendiri bagi karyawan dalam melakukan pekerjaannya. Kepuasan kerja dan motivasi kerja sangat berkaitan langsung dengan komitmen organisasional karyawan. Sehingga hal ini meningkatkan peran serta karyawan dalam kemajuan organisasi (Rizwan et al., 2014). Peningkatan motivasi kerja yang dirasakan oleh karyawan dapat mempengaruhi tingkat komitmen organisasional karyawan. Karyawan yang merasa puas dengan pekerjaan akan termotivasi untuk meningkatkan kinerja sehingga akan meningkatkan keberhasilan perusahaan. Karyawan yang bekerja dengan senang hati dan tanpa adanya paksaan akan memberikan hasil yang baik dan akan menumbuhkan komitmen organisasional karyawan terhadap perusahaan (Dina, 2012).

\section{Hubungan Antar Variabel}

\section{Hubungan antara Kompensasi terhadap Kinerja Karyawan}

Kompensasi atau imbalan kerja merupakan pemberian kepada pegawai atau sesuatu yang diterima pegawai sebagai balas jasa atas prestasinya kepada perusahaan dalam melaksanakan pekerjaan (Wekesa dan Nyaroo, 2013). Imbalan yang bersumber dari luar atau disebut juga dengan imbalan ekstrinsik terutama imbalan yang berbentuk uang seperti gaji, tunjangan dan lain-lain. Osibanjo et al. (2014) mendefenisikan kompensasi sebagai pemberian imbalan berbentuk materi kepada pegawai atau sesuatu yang diterima pegawai sebagai balas jasa atas prestasinya kepada perusahaan dalam melaksanakan pekerjaan. Imbalan ekonomi diberikan dalam bentuk gaji, upah, tunjangan, bonus, insentif dan lain-lain.

Tingkat kompensasi yang baik pada sebuah organisasi merupakan cara bagi perusahaan agar para karyawan berkinerja tinggi, karena memotivasi individu untuk melakukan pekerjaan dengan lebih baik sebagai kontribusi pada perusahaan tempatny bekerja. Penelitian telah menunjukkan bahwa kompensasi memainkan peran penting dalam menarik dan mempertahankan performa karyawan terbaik. Hong et al., (2013) mengemukakan bahwa organisasi harus memastikan bahwa kompensasi yang memuaskan akan dapat meningkatkan kinerja yang luar biasa dari karyawan. Namun, kompensasi bukanlah merupakan satu-satunya jaminan untuk menarik dan mempertahankan karyawan yang berkinerja tinggi atau meningkatkan kinerja organisasi dan produktivitas.

Dessler (2013) menyatakan bahwa kompensasi dapat dibedakan menjadi dua jenis, yaitu kompensasi finansial dan kompensasi non finansial. Kompensasi finansial terdiri dari kompensasi finansial langsung (direct financial compensation) dan kompensasi finansial tidak langsung (indirect financial compensation). Kompensasi finansial langsung terdiri dari gaji, upah, bonus dan komisi. Sedangkan kompensasi finansial tidak langsung disebut juga dengan tunjangan, yakni meliputi semua imbalan finansial yang tidak tercakup dalam kompensasi langsung. Kompensasi non finansial (non financial compensation) terdiri dari kepuasan yang diterima baik dari pekerjaan itu sendiri, seperti tanggung jawab, peluang akan pengakuan, peluang adanya promosi, atau dari lingkungan psikologis dan atau fisik dimana orang tersebut berada, seperti rekan 
kerja yang menyenangkan, kebijakan-kebijakan yang sehat, adanya kafetaria, sharing pekerjaan, minggu kerja yang dipadatkan dan adanya waktu luang.

Bukti empiris menunjukkan bahwa imbalan untuk kinerja merupakan cara bagi manajemen yang dapat digunakan untuk membuat sebuah organisasi berkinerja tinggi, karena memotivasi individu untuk melakukan lebih baik sebagai kontribusi dan upaya karyawan yang diakui, bernilai dan dihargai. Penelitian telah menunjukkan bahwa kompensasi memainkan peran penting dalam menarik dan mempertahankan kinerja karyawan terbaik. Bowra et al., (2011) mengemukakan bahwa organisasi harus memastikan bahwa kompensasi yang memuaskan akan dapat meningkatkan kinerja yang luar biasa dari karyawan. Penelitian terdahulu menyimpulkan adanya hubungan yang signifikan antara kompensasi dengan kinerja karyawan antara lain penelitian dari Osibanjo et al. (2014), Hong et al., (2013), dan Yvonne et al. (2014).

\section{Hubungan antara Motivasi terhadap Kinerja Karyawan}

Motivasi merupakan akibat dari suatu hasil yang ingin dicapai oleh seseorang dan perkiraan yang bersangkutan bahwa tindakannya akan mengarah kepada hasil yang diinginkannya. Motivasi dipicu oleh usaha manusia untuk memenuhi kebutuhan Aktualisasi diri, merupakan dorongan untuk menjadi seseorang atau sesuai ambisinya yang mencakup pertumbuhan, pencapaian potensi, dan pemenuhan kebutuhan diri (Mathis \& Jackson, 2001). Menurut Khan et al., (2010), di saat lingkungan bisnis organisasi di semua industri sedang mengalami perubahan yang cepat, motivasi memberikan pengaruh pada kinerja karyawan. Karyawan yang termotivasi pada pekerjaannya akan meningkatkan kinerjanya. Oleh karena itu, memotivasi karyawan untuk melakukan yang terbaik adalah kunci peningkatan kinerja karyawan dan motivasi berpengaruh signifikan terhadap kinerja pegawai dan kepuasan kerja (Dina, 2012).

\section{Hubungan antara Komitmen Organisasi dengan Kinerja Karyawan}

Komitmen organisasi adalah perasaan dedikasi untuk satu yang mempekerjakan organisasi, kesediaan untuk bekerja sulit bagi majikan, dan niat untuk tetap dengan organisasi (Ahmad et al., 2014). Menurut Ali et al., (2011) komitmen organisasi sebagai faktor yang mempromosikan keterlibatan seorang individu terhadap sebuah organisasi. Karyawan dianggap sebagai berkomitmen untuk sebuah organisasi jika mereka rela melanjutkan hubungan mereka dengan organisasi dan mencurahkan banyak upaya untuk mencapai tujuan organisasi. Tingginya tingkat komitmen organisasi yang tinggi akan menyebabkan peningkatan kinerja dan efektivitas baik individu dan tingkat organisasi. Beberapa peneliti sebelumnya menemukan hubungan signifikan antara komitmen organisasi dan kinerja karyawan yaitu Li (2014), Ahmad et al., (2014), Jie et al., (2013), Ahmad et al., (2010), Memari et al. (2013) dan Ali et al., (2011).

\section{Pengaruh antara Pelatihan Kerja terhadap Kinerja Karyawan}

Menurut Farooq dan Khan (2011), pelatihan merupakan elemen penting dalam memproduksi sumber daya manusia. Investasi dalam program pelatihan dapat membuat karyawan merasa hutang budi kepada perusahaan. Pelatihan dibutuhkan bagi karyawan untuk melakukan pekerjaan tertentu karena pekerjaan memerlukan keterampilan khusus dan pengetahuan supaya pekerjaan tersebut akan jauh lebih mudah untuk melakukan, dan ini juga merupakan sebuah kelebihan bagi karyawan. Pelatihan terhadap sumber 
daya manusia memiliki dampak yang positif terhadap kinerja karyawan karena ada korelasi yang sangat positif.

Pelatihan merupakan salah satu usaha dalam meningkatkan mutu sumber daya manusia dalam lingkungan perusahaan.Karyawan baik yang baru ataupun yang sudah lama bekerja perlu mengikuti pelatihan karena daya tuntutan pekerjaan yang dapat berubah akibat perubahan lingkungan kerja, strategi dan lain sebagainya. Pelatihan bukanlah tujuan, melainkan suatu alat dari manajemen untuk mencapai tujuan perusahaan yang mana merupakan usaha dan tanggung jawab pimpinan tertinggi terhadap karyawan yang menjadi tanggung jawabnya. Menurut Ameeq dan Hanif (2013), pelatihan memberikan karyawan keterampilan kerja, kemampuan, dan pengetahuan yang diperlukan dalam sebuah pekerjaan. Sebuah organisasi tertarik untuk berinvestasi dalam pelatihan kerja untuk karyawan dan memberikan kepercayaan diri dan mengandalkan mereka dimasa depan dengan pekerjaan yang lebih effektif.

Ameeq dan Hanif (2013) menyatakan pelatihan kerja yang formal akan lebih efektif dan bermakna dibandingkan dengan pelatihan kerja yang tidak formal. Pelatihan merupakan proses berkesinambungan, yang terus menerus diperbaharui sesuai dengan persyaratan individu. Kebutuhan pelatihan akan bervariasi sehingga tidak bisa dipastikan bahwa industri maupun organisasi harus melakukan pelatihan kerja setiap tahun, setengah tahun, atau seperempat tahun. Jenis pelatihan bergantung pada sifat pelatihan kerja, pelatih yang berasal dari luar organisasi akan membawa pengetahuan yang luas, penting dan beragam untuk berbagi pengetahuan dengan karyawan. Berdasarkan hasil penelitian sebelumnya dari Iqbal, Ahmad dan Javaid (2014) dan Farooq dan Khan (2011) menyimpulkan bahwa pelatihan kerja memiliki hubungan yang positif terhadap kinerja karyawan.

\section{Model Penelitian dan Perumusan Hipotesis}

Berdasarkan kerangka pemikiran teoritis yang dipaparkan diatas, maka penulis merumuskan model penelitian sebagai berikut:

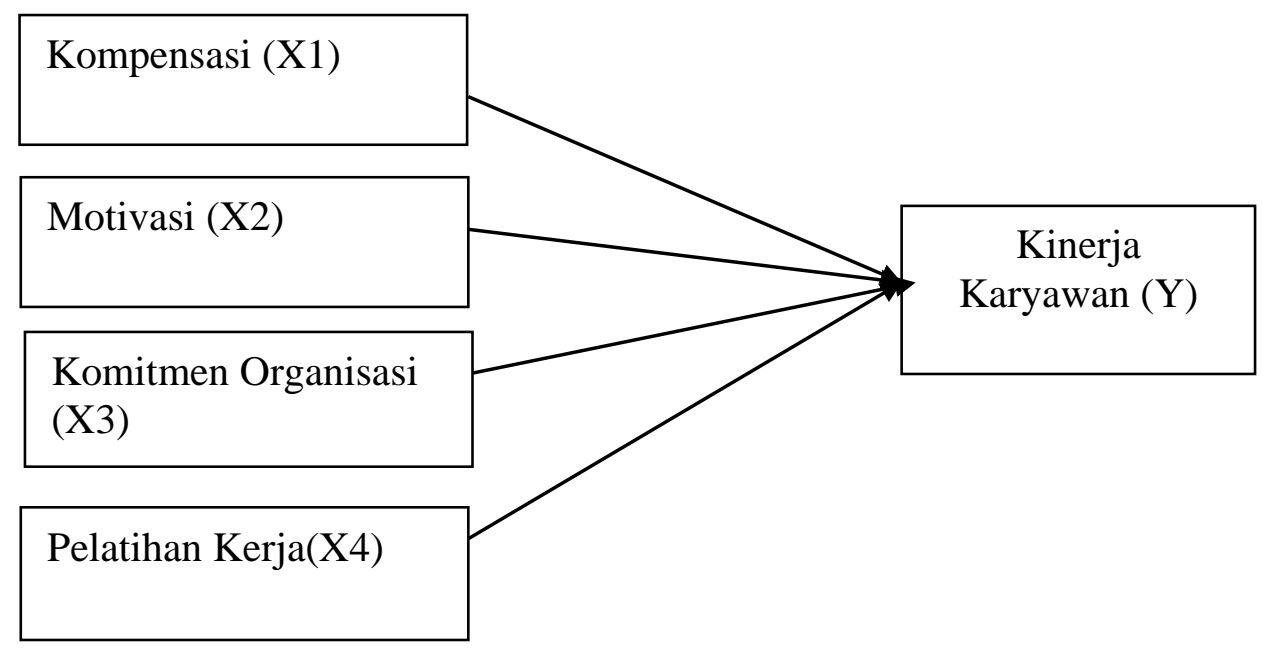

Berdasarkan model penelitian diatas, maka penulis merumuskan hipotesis dari penelitian diatas sebagai berikut : 
Hipotesis 1 : Kompensasi (X1) berpengaruh signifikan positif terhadap Kinerja Karyawan (Y)

Hipotesis 2 : Motivasi (X2) berpengaruh signifikan positif terhadap Kinerja Karyawan (Y)

Hipotesis 3 : Komitmen Organisasi (X3) berpengaruh signifikan positif terhadap Kinerja Karyawan (Y)

Hipotesis 4 :Pelatihan Kerja (X4) berpengaruh signifikan positif terhadap Kinerja Karyawan (Y)

\section{METODOLOGI PENELITIAN}

Bila ditinjau dari segi tujuan penelitian, maka penelitian ini termasuk dalam kategori penelitian dasar yang bertujuan untuk mengembangkan teori, dimana penelitian ini digunakan hanya untuk melakukan penelitian di lingkungan akademik (Indriantoro \& Supomo, 2012). Penelitian ini disusun untuk menjadi suatu karya ilmiah yang bertujuan untuk pengembangan ilmu pengetahuan. Namun apabila ditinjau dari segi permasalahannya, maka penelitian ini termasuk dalam penelitian kausal komparatif (Indriantoro \& Supomo, 2012).

\section{Objek Penelitian}

Populasi dalam penelitian ini adalah keseluruhan karyawan dari lima bank terbesar dari segi aset secara nasional yang beroperasi di Batam yaitu Bank Mandiri, Bank Rakyat Indonesia, Bank Central Asia, Bank Negara Indonesia dan Bank CIMB Niaga. Sampel penelitian sebanyak 240 orang karyawan bank. Karyawan bank dipilih sebagai objek penelitian karena pertumbuhan dan persaingan dibidang perbankan yang semakin ketat sehingga hal ini menuntut karyawan bank untuk dapat memberikan kinerja yang lebih baik agar perusahaan tetap dapat bersaing dengan bank lainnya yang juga terus maju dan berkembang dalam inovasi jasa yang ditawarkan dan pelayanan.

\section{Teknik Pengumpulan Data}

Teknik pengumpulan data dalam penelitian ini adalah dengan membagikan kuesioner secara langsung kepada responden dan memberikan penjelasan sepenuhnya jika diperlukan. Sumber data yang digunakan dalam penelitian ini adalah sumber data primer dan sekunder. Jumlah kuesioner yang disebarkan adalah sebanyak 240 kepada responden yang merupakan karyawan dari lima kantor cabang bank nasional yang berada di Batam. Kuesioner disebarkan dengan metode purposive sampling, yaitu metode pemilihan sampel secara tidak acak yang informasinya diperoleh dengan menggunakan pertimbangan tertentu sebagai sampel (Indriantoro \& Supomo, 2012). Kuesioner dibagikan langsung kepada karyawan bank dengan mendatangi masing masing bank yang menjadi objek penelitian dan mengambilnya kembali beberapa hari kemudian.

Penelitian ini menggunakan data primer dan sekunder. Data primer diperoleh dari objek penelitian dengan cara memberikan kuesioner kepada responden dan mengumpulkannya kembali sedangkan data sekunder adalah data yang diperoleh dari pihak lain, seperti dari internet, data organisasi, jurnal dan buletin. Data sekunder biasanya berwujud data dokumentasi atau data laporan yang telah tersedia (Indriantoro dan Supomo, 2012). 


\section{HASIL PENELITIAN}

\section{Hasil Uji Outlier}

Berdasarkan hasil pengujian terhadap 240 responden, tidak terdapat nilai $z$-score yang lebih besar dari 3,0 atau lebih kecil -3,0. Semua responden di uji dalam analisis berikutnya karena dianggap wajar dalam memberikan respon terhadap kuesioner. Nilai yang kurang atau lebih dari batas z-score akan dianggap menyimpang dan tidak dianalisa lebih lanjut (Ghozali, 2016)

\section{Hasil Uji Validitas}

Dari hasil uji validitas ini, ditemukan bahwa semua pernyataan valid dan bisa diikut sertakan dalam proses pengolahan data selanjutnya. Uji akan dinyatakan valid jika mempunyai nilai factor loading di atas 0,6 (Ghozali, 2016).

\section{Hasil Uji Reliabilitas}

Setelah melakukan uji reliabilitas, diperoleh nilai Cronbach alpha semua variabel melebihi nilai batas konsistensi 0,6 (Ghozali, 2016) sehingga semua variabel yang digunakan dalam penelitian ini dinyatakan reliabel.

\section{Hasil Uji Normalitas}

Melalui uji normalitas menunjukkan data memiliki distribusi yang normal dan menyebar mengikuti garis diagonal, disimpulkan bahwa semua model regresi yang dipergunakan dalam penelitian ini layak dipakai karena memenuhi asumsi normalitas.

\section{Hasil Uji Multikolinearitas}

Hasil uji multikolinearitas terhadap variabel bebas tidak ditemukan nilai yang menunjukkan nilai tolerance di bawah 0,10, yang artinya tidak ada korelasi antar variabel bebas. Hasil pengujian menunjukkan nilai VIF kurang dari 10 dan nilai tolerance lebih dari 0,1 . Jadi, dapat disimpulkan bahwa tidak terdapat multikolinearitas antar variabel bebas dalam regresi (Ghozali, 2016).

\section{Hasil Uji Heterokedastisitas}

Hasil uji heterokedastisitas dengan uji glejser terhadap variabel independen dan dependen menunjukkan bahwa variabel independen dan dependen terdistribusi secara normal dengan nilai di atas 0,05 maka dapat disimpulkan tidak terjadi heterokedastisitas dalam variabel yang diuji.

\section{Hasil Uji F}

Uji $F$ digunakan untuk menunjukkan apakah semua variabel independen mempunyai pengaruh secara bersama sama terhadap variabel dependen. Uji F dilakukan dengan melihat nilai signifikansi. Dari hasil uji $\mathrm{F}$ diperoleh data bahwa tingkat probabilitas sebesar 0,000. lebih kecil dari 0,05 sehingga model regresi tersebut dapat digunakan untuk memprediksi atau mengukur variabel kinerja karyawan sebagai variabel dependen. 


\section{Hasil Uji t}

Berdasarkan hasil uji t diketahui bahwa nilai signifikansi sebesar 0,000 dan nilai beta sebesar 0,267 sehingga dapat disimpulkan bahwa terdapat pengaruh signifikan antara variabel kompensasi terhadap kinerja karyawan. Temuan ini menunjukkan bahwa tingkat kompensasi dan penerapan aturan yang berkaitan dengan kebijakan kompensasi dalam sebuah organisasi berdampak signifikan terhadap kinerja karyawan. Hasil penelitian ini sesuai dengan penelitian sebelumnya dari Iqbal et al., (2014), Wekesa dan Nyaroo (2013), Hameed et al. (2012), Osibanjo et al. (2014), Rizal et al. (2014) dan Ibrar dan Khan (2015).

Berdasarkan hasil uji t diketahui bahwa nilai signifikansi variabel motivasi kerja sebesar 0,005 dan nilai beta sebesar 0,285 sehingga dapat disimpulkan bahwa terdapat pengaruh signifikan antara motivasi terhadap kinerja karyawan. Temuan ini menunjukkan bahwa motivasi kerja karyawan berdampak signifikan terhadap peningkatan kinerja karyawan. Hasil penelitian ini sesuai dengan penelitian sebelumnya dari Dina (2012), Rizwan et al. (2014), Zameer et al., (2014), Kiruja dan Mukuru (2013), Rizal et al. (2014) dan Li (2014)

Berdasarkan hasil uji t diketahui bahwa nilai signifikansi variabel motivasi kerja sebesar 0,003 dan nilai beta sebesar 0,246 sehingga dapat disimpulkan bahwa komitmen organisasi berpengaruh signifikan terhadap kinerja karyawan. Temuan ini menunjukkan bahwa semakin tinggi tingkat komitmen karyawan terhadap perusahaan maka akan berdampak signifikan terhadap peningkatan kinerja karyawan. Hasil penelitian ini sesuai dengan penelitian sebelumnya dari Ahmad et al., (2014), Ali et al., (2011), Memari et al. (2013), Rizal et al. (2014) dan Li (2014)

Berdasarkan hasil uji t diketahui bahwa nilai signifikansi variabel motivasi kerja sebesar 0,000 dan nilai beta sebesar 0,294 sehingga dapat disimpulkan bahwa dalam penelitian ini bahwa variabel pelatihan kerja berpengaruh signifikan terhadap kinerja karyawan. Hasil penelitian ini menunjukkan bahwa pelatihan kerja yang sesuai dengan pekerjaan karyawan akan membantu meningkatkan kinerja dari karyawan. Hasil penelitian ini sesuai dengan penelitian sebelumnya dari Iqbal et al., (2014), Rizwan et al. (2014), Farooq dan Khan (2011).

\section{Hasil Uji Koefisien Determinasi $\left(\mathbf{R}^{2}\right)$}

Uji koefisien determinasi $\left(\mathrm{R}^{2}\right)$ digunakan untuk menunjukkan adanya korelasi atau hubungan antara variabel dependen dan independen. Angka adjusted $\mathrm{R}^{2}$ sebesar 0,548 sehingga bisa disimpulkan bahwa kemampuan variabel independen dalam menjelaskan variabel dependen adalah sebesar 54,8\% sedangkan sisanya sebesar 45,2\% dijelaskan oleh variabel lain yang tidak diteliti dalam penelitian ini seperti keterlibatan kerja (Iqbal et al., 2014) dan kepuasan kerja (Ahmad et al., 2014).

\section{KESIMPULAN}

Setelah pembahasan dalam bab sebelumnya mengenai hubungan antara variabel independen kompensasi, motivasi, komitmen organisasi dan pelatihan kerja maka dapat disimpulkan pengaruh dan hubungan signifikansi dengan kinerja karyawan sebagai variabel dependen dalam penelitian ini. Disimpulkan bahwa terdapat pengaruh signifikan antara variabel kompensasi terhadap kinerja karyawan. Temuan ini menunjukkan bahwa tingkat kompensasi dan penerapan aturan yang berkaitan dengan kebijakan kompensasi dalam sebuah organisasi akan berdampak signifikan terhadap 
kinerja karyawan. Dapat disimpulkan bahwa terdapat pengaruh signifikan antara motivasi terhadap kinerja karyawan. Temuan ini menunjukkan bahwa motivasi kerja karyawan akan berdampak signifikan terhadap peningkatan kinerja karyawan bank di Batam. Disimpulkan bahwa komitmen organisasi berpengaruh signifikan terhadap kinerja karyawan. Temuan ini menunjukkan bahwa semakin tinggi tingkat komitmen karyawan terhadap perusahaan maka akan berdampak signifikan terhadap peningkatan kinerja karyawan bank di Batam. Dapat disimpulkan bahwa dalam penelitian ini bahwa variabel pelatihan kerja berpengaruh signifikan terhadap kinerja karyawan. Hasil penelitian ini menunjukkan bahwa pelatihan kerja yang sesuai dengan pekerjaan karyawan akan membantu meningkatkan kinerja dari karyawan bank di Batam.

\section{UCAPAN TERIMA KASIH}

Penulis mengucapkan terimakasih kepada Kaprodi Manajemen Fakultas Ekonomi Universitas Internasional Batam dan juga teman teman peneliti yang telah mendukung dan memberikan semangat pada peneliti untuk melakukan penelitian ini.

\section{DAFTAR PUSTAKA}

Ahmad, N., Iqbal, N \& Hamad, N (2014) Impact of Organizational Commitment and Employee Performance on the Employee Satisfaction. International Journal of Learning, Teaching and Educational Research Vol. 1, No. 1, pp. 84-92

Al-Qudah, M. K., Osman, A., Halim, M. S., \& Shatanawi, H. A., (2014). The Effect Of Human Resources Management Practices On Employee Performance. International Journal of Academic Research in Business and Social Sciences, Vol. 4, No. 4.

Ali, N, Mehmud, S.T \& Khan, Z (2011) Relationship between Organizational Commitment and Perceived Employees Performance. International Journal of Human Resource Management, 17(1), 86-105.

Ameeq, A. dan Hanif, F (2013) Impact of Training on Employee's Development and Performance in Hotel Industry of Lahore, Pakistan. Journal of Business Studies Quarterly 2013, Volume 4, Number 4

Amin, A., Saeed,R., Lodhi,R.W., Simra,M., Iqbal, A. \& Tehreem, R. (2012) The Impact of Employees Training On the Job Performance in Education Sector of Pakistan. Middle-East Journal of Scientific Research 17 (9): 1273-1278, 2013.

Asim, M (2013). Impact of Motivation on Employee Performance with Effect of Training: Specific to Education Sector of Pakistan. International Journal of Scientific and Research Publications, Volume 3, Issue 9, September 20131 ISSN 2250-3153

Dessler, G. (2013) Human Resource Management Thirteenth Edition. New Jersey: Prentice Hall

Dina, M.L (2012) Connection between Job Motivation, Job Satisfaction and Work Performance in Romanian Trade Enterprises. Annalysis of "Dunarea de Jos" University of Galati Fascicle I. Economics and Applied Informatics.

Elnaga, A. \& Imran, A. (2013) The Effect of Training on Employee Performance. European Journal of Business and Management Vol.5, No.4, 2013 
Farooq, M dan Khan, M.A. (2011) Impact of Training and Feedback on Employee Performance Far East Journal of Psychology and Business Vol. 5 No. 1 October 2011

Ghozali, Imam. (2016). Aplikasi Analisis Multivariate dengan Program IBM SPSS 23. Semarang: BPFE Universitas Diponegoro.

Hair, J.F., Black, W.C., Babin, B.J., \& Anderson, R.E. (2010). Multivariate Data Analysis. Seventh Edition. Prentice Hall, Upper Saddle River, New Jersey.

Hameed, A; Ramzan, M; Zubair, H.K \& Ali, G (2012) Impact of Compensation on Employee Performance (Empirical Evidence from Banking Sector of Pakistan. International Journal of Business and Social Science Vol. 5.2

Hong, L.C., Hamid, N. dan Salleh, N.M (2013) A Study on the Factors Affecting Job Performance amongst Employees of a Factory in Seremban, Malaysia. Business Management Dynamics Vol.3, No.1, Jul 2013, pp.26-40

Hussain, T. \& Rehman, S.S. (2013) Do Human Resource Management Practices Inspire Employees' Retention? Research Journal of Applied Sciences, Engineering and Technology 6(19): 3625-3633, 2013

Indriantoro, N \& Supomo, B (2009). Metedologi Penelitian Bisnis. Yogyakarta : Edisi Pertama, Penerbit BPFE.

Iqbal, N., Ahmad, N dan Javaid, K (2012) Impact of Training on Employee Performance in the Context of Telecommunication Sector. International Letters of Social and Humanistic Sciences 6 (2014) 60-73 ISSN 2300-2697

Ibrar, M \& Khan, O. (2015) The Impact of Reward on Employee Performance. International Letters of Social and Humanistic Sciences Vol. 52 (2015) pp 95103

Jagero, N. Komba, H.V \& Mlingi, M.D (2012) Relationship between on the Job Training and Employee's Performance in Courier. Companies in Dar es Salaam, Tanzania. International Journal of Humanities and Social Science Vol. 2 No. 22

Jie, F; Aries, S \& Rizqi M (2013) Analysis of the Effect of Attitude toward Works, Organizational Commitment and Job Satisfaction on Employee's Job Performance. European Journal of Business and Social Sciences, Vol. 1, No. 10, pp 15-24

Khan, A.H; Nawaz, M.M \& Aleem, M (2010) Impact of Job Satisfaction on Employee Performance: An Empirical Study of Autonomous Medical Institutions of Pakistan. African Journal of Business Management Vol. 6 (7), pp. 2697-2705, 22 February, 2012

Kiruja, E.K \& Kabare, K (2013) Linking Work Environment with Employee Performance in Public in Kenya. International Journal of Advances in Management and Economics. Vol.2 Issue 4,83-91

Li, X (2014) An Empirical Study on Public Service Motivation and the Performance of Government Employee in China. Canadian Social Science Vol.4 No.2 April 2014

Mathis, Robert. L \& Jackson John. H, (2001). Manajemen Sumber Daya Manusia, Jilid 1, Salemba Empat, Jakarta

Memari, N., Mahdieh, O \& Marnani, A.B (2013) The impact of Organizational Commitment on Employees Job Performance. Interdisciplinary Business Research Vol 5, NO 5 
Njanja, W.L., Maina, R.N, Kibet, L.K., \& Njagi, K (2013) Effect of Reward on Employee Performance: A Case of Kenya Power and Lighting Company Ltd., Nakuru, Kenya. International Journal of Business and Management; Vol. 8, No. $21 ; 2013$

Odunlami, I.B., \& Matthew, A.O (2014) Compensation Management and Employees Performance in the Manufacturing Sector, A Case Study of a Reputable Organization in the Food and Beverage Industry. International Journal of Managerial Studies and Research Vol. 2, Issue 9, October 2014

Oladejo, M.O \& Oluwaseun, Y (2014) An Assessment of the impact of Compensation Plan on workers Performance of selected Quoted Food and Beverages Manufacturing Companies in Nigeria. Journal of Business and Management Vol. $16 / 7$

Osibanjo, O.A., Adeniji, A.A., Falola, H.O., \& Heirsmac, P.T (2014) Compensation Packages: a Strategic Tool for Employees' Performance and Retention. Leonardo Journal of Sciences ISSN 1583-0233 Issue 25, 2014 p. 65-84

Rizal, M., Idrus, M.S., Djumahir \& Mintarti, R (2014) Effect of Compensation on Motivation, Organizational Commitment and Employee Performance. International Journal of Business and Management Invention ISSN: 2319 8028

Rizwan, M (2014) A Comparative Analysis of the Factors Effecting the Employee Motivation and Employee Performance in Pakistan. International Journal of Human Resource Studies 2162-3058 2014, Vol. 4, No. 3

Shabbir, M.S (2014). The Impact of Human Resource Practice on Employee Perceived Performance in Pharmaceutical Sector of Pakistan. African Journal of Business Management, Vol. 8 (15) pp 626-632

Thamrin, H.M (2012) The Influence of Transformational Leadership and Organizational Commitment on Job Satisfaction and Employee Performance. International Journal of Innovation, Management and Technology, Vol. 3, No. 5, October 2012

Wekesa, J.N \& Nyaroo. S. (2013). Effect of Compensation on Performance of Public Secondary School Teachers in Eldoret Municipality Kenya. International Journal of Scientific and Research Publications, Volume 3, Issue 6, June 2013

Yvonne, W., Rahman. R.H.A dan Long, C.S (2014) Employee Job Satisfaction and Job Performance: A Case Study in a Franchised Retail-Chain Organization. Research Journal of Applied Sciences, Engineering and Technology 8 (17): 1875-1883, 2014

Zameer, H., Ali, S., Nisar, W dan Amir, M. (2014) The Impact of the Motivation on the Employee's Performance in Beverage Industry of Pakistan. International Journal of Academic Research in Accounting, Finance and Management Sciences Vol. 4, No.1, January 2014, pp. 293-298 